\title{
Laboratory diagnosis of gastrointestinal bleeding
}

\author{
L. STEINGOLD AND A. A. ROBERTS \\ From St. Andrew's Hospital, London, E.3
}

SYNOPSIS The value of four tests to detect occult alimentary blood loss has been compared in normal subjects, in patients with and without alimentary disease, and in patients with congestive heart failure, and the sensitivities of these tests have been compared using suspensions of blood alone and blood in faeces. The Occultest proved almost as sensitive as did the benzidine test in the detection of faecal blood loss, and, if combined with a spectroscopic test for protoporphyrin, minimizes the number of 'false' positive results that are reported. Such false positive results will inevitably occur but are reduced by dietary restriction before the test is made.

We have been investigating the use of laboratory methods in the diagnosis of ulceration and neoplasm of the alimentary tract for about seven years. During this period benzidine became difficult to obtain following the observations by Case, Hosker, Drever, and Pearson (1954) on the very high incidence of neoplasm of the urinary bladder in workers engaged in the manufacture of this and certain other substances. We then decided to change to orthotolidine, which appeared to be the most popular alternative reagent for the demonstration of faecal occult blood, and about this time obtained a supply of Haematest tablets. While we were interested in studying a method less sensitive than the benzidine test, these proved too insensitive for our purpose and we were offered Occultest tablets, designed primarily for the demonstration of blood in urine. Both of these are orthotolidine preparations containing strontium peroxide.

The purpose of this paper is to describe comparative observations on a benzidine test, an orthotolidine test, and these two tablet tests, and to discuss their value and that of the spectroscopic examination of faeces for protoporphyrin in the diagnosis of alimentary bleeding.

\section{METHODS}

In the benzidine and orthotolidine tests analytical reagent quality chemicals and acid-washed glassware only are used.

BENZIDINE TEST A portion of faeces the size of a pea is suspended in $5 \mathrm{ml}$. of distilled water and boiled for five minutes. This time is not critical and boiling for up to half-an-hour does not appear to alter the sensitivity of this or the orthotolidine test. In a test-tube, to 1 in. of a saturated solution of benzidine in glacial acetic acid is added an equal volume of hydrogen peroxide, $10 \mathrm{vol}$. strength. The solutions are mixed and a little of the cooled faecal suspension is gently run on its surface. The tube is tapped to allow slight admixture and the result read after one minute.

Strong positive ..... deep blue ring

Moderate positive. . . deep green ring

Weak positive..... pale green ring

Negative........ no colour change

ORTHOTOLIDINE TEST A $4 \%$ solution of orthotolidine in $95 \%$ ethyl alcohol is prepared. This is stored in a dark, cool cupboard and appears to keep for some months. For use a 1 in 5 dilution is made in glacial acetic acid. A faecal suspension, as for the benzidine test, is prepared. To $1 \mathrm{ml}$. of orthotolidine reagent are added $0.25 \mathrm{ml}$. of the faecal suspension and $0.25 \mathrm{ml}$. of hydrogen peroxide, $20 \mathrm{vol}$. strength, and mixed. The result is read after three minutes.

Strong positive...... dark green

Moderate positive ... medium green

Weak positive ...... pale green

Negative ........ no colour change

OCCULTEST METHOD A thin smear of faeces is made on the filter paper provided with the tablets. (It is stated that ordinary grades of filter paper may give false results.) An Occultest tablet is placed on the smear and one drop of distilled water placed on it. Five to 10 seconds later a second drop is added so that the water runs over the edge of the tablet on to the faecal smear. A reading is taken after two minutes.

Strong positive ..... deep blue colour extending widely beyond tablet

Moderate positive... medium blue colour extending slightly beyond tablet

Weak positive ...... blue-green colour seen only when the tablet is removed

Negative ........ no colour change 
TABLE I

SENSITIVITY OF TESTS ON DILUTIONS OF BLOOD IN WATER AND IN FAECES

\begin{tabular}{|c|c|c|c|c|c|c|}
\hline \multirow[t]{2}{*}{ Test } & \multicolumn{6}{|c|}{ Dilutions of Blood } \\
\hline & $1 / 500$ & $1 / 2,500$ & $1 / 12,500$ & $1 / 62,500$ & $1 / 312,500$ & $1 / 1,562,500$ \\
\hline \multicolumn{7}{|l|}{ Dilutions of Blood- } \\
\hline $\begin{array}{l}\text { Benzidine } \\
\text { Occultest } \\
\text { Orthotolidine } \\
\text { Hematest }\end{array}$ & $\begin{array}{l}+++ \\
+++ \\
+++ \\
+++\end{array}$ & $\begin{array}{l}+++ \\
+++ \\
++ \\
+++\end{array}$ & $\begin{array}{l}++ \\
++ \\
+ \\
++\end{array}$ & $\begin{array}{l}+ \\
++ \\
+ \\
+\end{array}$ & $\begin{array}{l}+ \\
+ \\
\text { Trace } \\
\text { Trace }\end{array}$ & $\begin{array}{l}- \\
- \\
-\end{array}$ \\
\hline \multicolumn{7}{|c|}{ Dilutions of Blood in Faeces } \\
\hline $\begin{array}{l}\text { Benzidine } \\
\text { Occultest } \\
\text { Orthotolidine } \\
\text { Hematest }\end{array}$ & $\begin{array}{l}+++ \\
+++ \\
+++ \\
+++\end{array}$ & $\begin{array}{l}+++ \\
++ \\
++ \\
+\end{array}$ & $\begin{array}{l}++ \\
+ \\
\text { Trace } \\
\text { Trace }\end{array}$ & $\begin{array}{l}+ \\
\text { Trace } \\
- \\
-\end{array}$ & $\begin{array}{l}+ \\
- \\
-\end{array}$ & $\begin{array}{l}- \\
- \\
-\end{array}$ \\
\hline
\end{tabular}

HEMATEST METHOD The method and interpretation are identical with those of the Occultest method, a Hematest tablet being substituted for an Occultest tablet.

SEPECTROSCOPIC EXAMINATION This is a semi-quantitative modification of the method described by Snapper (1919) for the demonstration of protoporphyrin, as the acid porphyrin, in faeces. About $30 \mathrm{~g}$. of faeces is ground up in an excess (about $100 \mathrm{ml}$.) of acetone and filtered. The treated faeces are given a further wash with about $50 \mathrm{ml}$. of acetone and allowed to dry. Five grams of the dried faeces is ground up in 10 to $15 \mathrm{ml}$. of a mixture of one part of glacial acetic acid to two of ethyl acetate and filtered into a $\frac{1}{2}$-in. test-tube and 8 to $10 \mathrm{ml}$. of filtrate is obtained. Then $4 \mathrm{ml}$. of $20 \%$ hydrochloric acid is added and the solutions mixed. Ether is added to $1 \mathrm{~cm}$. from the top of the tube and the tube shaken. The mixture is allowed to separate, and the lower layer examined in a Hartridge reversion spectroscope with the aperture set at a reading of 10 . The two absorption bands of acid protoporphyrin may be seen, a dense $\beta$ band between the yellow and green $(5650$ - 5500A, $\lambda=5572 \mathrm{~A}$ ) and a weaker $a$ band between the red and yellow $(6050-6000 \mathrm{~A}, \lambda=6024 \mathrm{~A})$, as described by Snapper (1919) and by Harrison (1947).

Strong positive..... both bands dense. The solution may require further dilution with acid for the bands to be defined in very strongly positive cases

Moderate positive ... $\beta$ band strong, $a$ band weak

Weak positive ..... $\beta$ band weak, $\alpha$ band invisible Negative ........ no band visible

Re-extraction of the dried faeces with ethyl acetateacetic acid gives negative results in all but strongly positive specimens. Diagnostic errors through incomplete extraction do not therefore occur.

\section{EXPERIMENTAL OBSERVATIONS}

The sensitivities of the four chemical methods were compared against a series of fivefold dilutions of blood in distilled water and of blood in a $10 \%$ emulsion of faeces. The results are shown in Table I.

These tests were carried out on specimens of oxalated venous blood, haemoglobin $96 \%$ (14 g. per $100 \mathrm{ml}$.). Tests using a specimen with a haemoglobin of $64 \%(9 \cdot 3 \mathrm{~g}$. per $100 \mathrm{ml}$.) gave slightly weaker results.

To demonstrate the quantitative relationship between the various intensities of reaction in the test for porphyrin, a hydrochloric acid solution of porphyrin was made up from a positive specimen of faeces and a series of dilutions of this in a $20 \%$ solution of hydrochloric acid prepared and examined. The results are shown in Table II.

TABLE II

EFFECT OF DILUTION ON PORPHYRIN REACTION

\begin{tabular}{lll}
$\begin{array}{l}\text { Concentration of Original } \\
\text { Acid Porphyrin Solution } \\
\text { (\%) }\end{array}$ & $\begin{array}{l}\text { Intensity of Spectroscopic } \\
\text { Findings }\end{array}$ & Symbol \\
\hline & & \\
\hline 100 & Intense positive & +++ \\
90 & Very strong positive & \\
80 & Strong positive & ++ \\
70 & Fairly strong positive & + \\
60 & Moderate positive & + \\
40 & Rather weak positive & \\
30 & Weak positive & - \\
20 & Weak positive & \\
10 & Trace & \\
& Negative & \\
Strong positive +++ & Moderate positive ++ \\
Weak positive + & Negative
\end{tabular}

Intensities greater than that shown by the " $100 \%$ " solution in this case are possible and not at all uncommon.

\section{SENSITIVITIES IN CLINICAL MATERIAL}

All five tests were performed on three series of consecutive specimens, totalling 295 specimens, submitted to the laboratory, from in-patients and 
out-patients, for routine investigation. The results are shown in Table III.

\section{TABLE III}

TESTS FOR OCCULT BLOOD AND PROTOPORPHYRIN IN CLINICAL MATERIAL STUDIED

\begin{tabular}{lcccc} 
Test & \multicolumn{2}{l}{ Results } & & \\
\cline { 2 - 5 } & Negative & + & ++ & +++ \\
\hline Benzidine & 112 & 47 & 62 & 74 \\
Occultest & 132 & 55 & 48 & 60 \\
Orthotolidine & 181 & 28 & 27 & 59 \\
Hematest & 207 & 46 & 24 & 18 \\
Protoporphyrin & 68 & 49 & 85 & 93 \\
Strong positive +++ & & Moderate positive ++ & Weak +
\end{tabular}

\section{RELATIONSHIP OF TESTS FOR OCCULT BLOOD AND PORPHYRIN TO CLINICAL FINDINGS}

Three series of cases were analysed to determine the relationship of these tests to clinical diagnosis. In all instances the specimens were obtained after the patient had been for three days on a diet free of meat and green vegetables. The series of cases were:

(1) NORMAL CONTROLS These were 30 in-patients not known at the time of the test to have alimentary disease.

(2) TEST SERIES This was a consecutive series of 67 in-patients from whom specimens were submitted for routine examination to exclude bleeding.

(3) SELECT SERIES This was a selected series of 31 cases from our records to illustrate the lack of correlation between tests for occult blood and the test for porphyrin.
(1) NORMAL CONTROLS Of these, 20 gave negative results with all four chemical tests and with the test for porphyrin, They suffered from a variety of clinical conditions, none being associated with alimentary tract disease. Details of the remainder are given in Table IV.

(2) TEST SERIES This series can be divided into the following groups:

I. Lesions of Upper Alimentary Canal Of the 30 verified cases, there were 14 duodenal ulcers, 14 gastric ulcers, one anastomotic ulcer, and one gastric carcinoma.

All of the unverified cases (11) presented with clinical findings indicative of peptic ulceration and were treated as such. Four were not radiographed. One showed a hiatus hernia but ulceration was not verified. Six were negative on barium meal examination.

In four cases specimens were submitted to check on healing in known cases of peptic ulceration. In three of these, previous tests had been carried out, the porphyrin test in all three being then strongly positive while the benzidine reactions were negative, moderate positive, and strong positive respectively. In a fifth case, $x$-ray examination suggested a prepyloric ulcer, but tests for occult blood by all four methods and for porphyrin were negative. At operation the only lesion found was the scar of an old healed duodenal ulcer.

II. Lesions of Lower Alimentary Canal Of these there were three cases of haemorrhoids, one of diverticulitis of the lower colon, one of granuloma of the transverse colon, and one gastro-jejuno-colic fistula. The last is included here since bleeding would present as though coming from the colon.

III. Congestive Cardiac Failure Three of these

TABLE IV

'NORMAL' CONTROLS GIVING POSITIVE TESTS

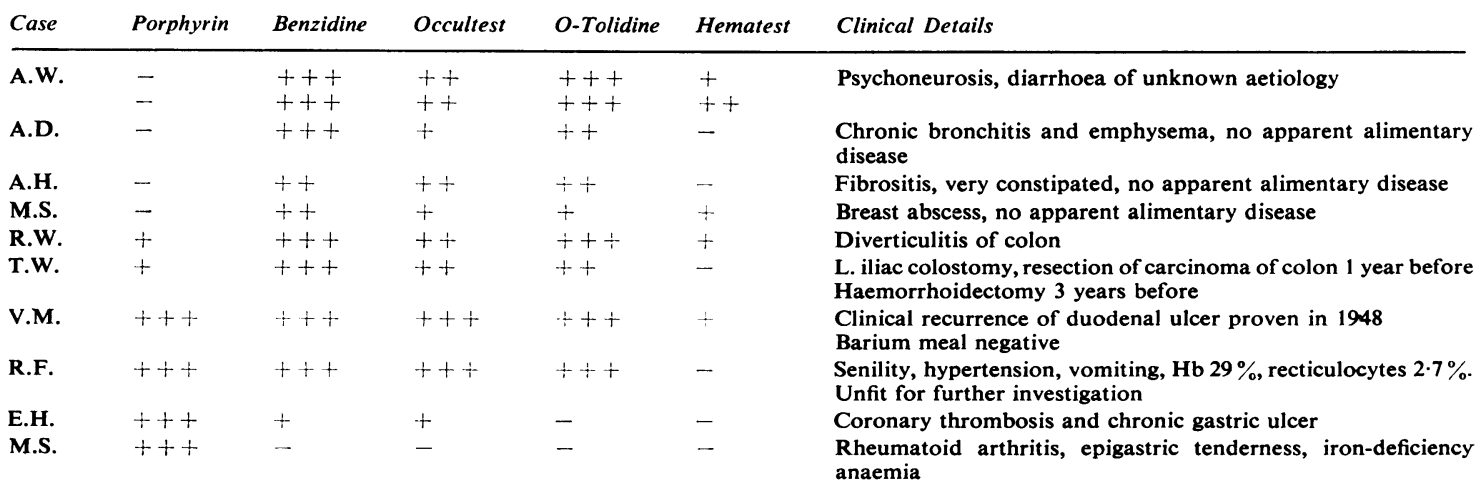


TABLE V

FAECAL FINDINGS IN TEST SERIES

\begin{tabular}{|c|c|c|c|c|c|c|}
\hline \multirow[t]{2}{*}{ Group } & \multirow[t]{2}{*}{ Diagnosis } & \multirow[t]{2}{*}{ Test } & \multicolumn{4}{|c|}{ Results } \\
\hline & & & $\mathbf{0}$ & + & ++ & +++ \\
\hline \multirow[t]{4}{*}{ I } & \multirow[t]{2}{*}{ Active lesions of upper alimentary canal } & Porphyrin & $3^{*}$ & $3^{*}$ & 10 & 25 \\
\hline & & $\begin{array}{l}\text { Benzidine } \\
\text { Occultest } \\
\text { Orthotolidine } \\
\text { Hematest }\end{array}$ & $\begin{array}{r}7 \\
11 \\
22 \\
23\end{array}$ & $\begin{array}{r}5 \\
11 \\
6 \\
10\end{array}$ & $\begin{array}{r}14 \\
7 \\
2 \\
3\end{array}$ & $\begin{array}{r}15 \\
12 \\
11 \\
5\end{array}$ \\
\hline & \multirow[t]{2}{*}{ Healed or healing lesions } & Porphyrin & 4 & 1 & 一 & 一 \\
\hline & & $\begin{array}{l}\text { Benzidine } \\
\text { Occultest } \\
\text { Orthotolidine } \\
\text { Hematest }\end{array}$ & $\begin{array}{l}2 \\
2 \\
3 \\
4\end{array}$ & $\begin{array}{l}1 \\
1 \\
2 \\
1\end{array}$ & $\begin{array}{r}1 \\
2 \\
- \\
-\end{array}$ & $\frac{1}{-}$ \\
\hline \multirow[t]{2}{*}{ II } & \multirow[t]{2}{*}{ Lesion of lower alimentary canal } & Porphyrin & 5 & $1 \dagger$ & - & 一 \\
\hline & & $\begin{array}{l}\text { Benzidine } \\
\text { Occultest } \\
\text { Orthotolidine } \\
\text { Hematest }\end{array}$ & $\frac{-}{1}$ & $\begin{array}{l}- \\
-\end{array}$ & $\begin{array}{r}1 \\
4 \\
2 \\
-\end{array}$ & $\begin{array}{l}5 \\
2 \\
3 \\
3\end{array}$ \\
\hline \multirow[t]{2}{*}{ III } & \multirow[t]{2}{*}{ Congestive cardiac failure } & Porphyrin & - & 一 & 2 & 2 \\
\hline & & $\begin{array}{l}\text { Benzidine } \\
\text { Occultest } \\
\text { Orthotolidine } \\
\text { Hematest }\end{array}$ & $\frac{-}{1}$ & $\frac{\overline{2}}{1}$ & $\frac{-}{1}$ & $\begin{array}{r}4 \\
2 \\
3 \\
-\end{array}$ \\
\hline \multirow[t]{2}{*}{ IV } & \multirow[t]{2}{*}{ No alimentary lesion } & Porphyrin & 3 & $3 \ddagger$ & - & - \\
\hline & & $\begin{array}{l}\text { Benzidine } \\
\text { Occultest } \\
\text { Orthotolidine } \\
\text { Hematest }\end{array}$ & $\begin{array}{l}3 \\
2 \\
5 \ddagger \\
4\end{array}$ & $\begin{array}{l}2 \\
3 \\
1 \\
2+\end{array}$ & $\begin{array}{l}1 \ddagger \\
1 \ddagger \\
- \\
-\end{array}$ & $\begin{array}{c}- \\
-\end{array}$ \\
\hline
\end{tabular}

Strong positive $+++\quad$ Moderate positive $++\quad$ Weak positive $+\quad$ Negative *Two of each of these groups of three cases were on antacid absorbents at the time of test t Granuloma of transverse colon $\ddagger$ Case of myeloid leukaemia included

TABLE VI

RESULTS IN SELECT SERIES

Diagnosis

\begin{tabular}{ll}
\cline { 2 - 2 } & 0 \\
\hline Pyloric or duodenal ulcer (20 cases) & 25 \\
Gastric ulcer (9 cases) & 12 \\
Anastomic or jejunal ulcer ( 2 cases) & 1
\end{tabular}

Strong positive $+++\quad$ Moderate positive ++

cases were due to chronic bronchitis and emphysema, and one to mitral stenosis with auricular fibrillation. None gave evidence of alimentary disease.

IV. Cases with No Alimentary Disease Five of these were, respectively, anaemia without bleeding, lobar pneumonia, hypertension, hysteria, and mild chronic oesophagitis. The sixth was a case of myeloid leukaemia with skin petechiae, in which somewhat positive results were obtained.

V. Incompletely Diagnosed Cases In these the possibility of an alimentary lesion was overshadowed by the major condition present, namely, cerebral tumour, carcinoma of bladder, carcinomatosis of unknown origin, carcinoma of lung, and appendix abscess in a senile patient. Positive results were obtained in these cases but as adequate investigation of the alimentary tract was impracticable, these are excluded from the discussion. The results of this series are shown in Table V.

In the complete series of 67 cases, the number of tests for occult blood which were negative in the presence of a moderately or strongly positive test for porphyrin were: benzidine, 6; Occultest, 10; orthotolidine, 22; Hematest, 24. 
(3) SELECT SERIES. This consisted of 45 tests on 31 cases. All patients were dieted for the test and all had lesions verified by radiography, gastroscopy, operation, or necropsy. They illustrate the occurrence of negative or weakly positive benzidine tests in cases of peptic ulceration and show the porphyrin findings in such cases. The results are shown in Table VI.

\section{DISCUSSION}

Since benzidine ceased to be available, workers who used it will now have changed to an alternative reagent and, in so doing, will no doubt have chosen a method of the same degree of sensitivity as the one to which they were accustomed. We have shown (Table I) that comparison of sensitivities against dilutions of blood in water can be very misleading, and that such comparisons should be made on dilutions of blood in a faecal emulsion or, better, by noting the results obtained by the methods under examination carried out in parallel on a consecutive series of clinical specimens. Against watery solutions of blood the benzidine test and the Occultest method are about equally sensitive, with the orthotolidine test and the Hematest method a little less sensitive. Faeces, however, appear to inhibit orthotolidine methods without apparently affecting the benzidine test, which thereby becomes much more sensitive, under these conditions, than the others. We have been unable to verify the inhibitory effect of faeces on benzidine reported by Needham and Simpson (1952), who used the Gregersen test. Tests on clinical material (Table III) verify the greater sensitivity of the benzidine method and show that, of the three orthotolidine tests described, the Occultest method is the most sensitive and the Hematest method the least.

It has been shown, in the case of the benzidine test by Gregersen (1919) and in the case of the orthotolidine test by Kohn and O'Kelly (1955), that by altering the proportion of reagents used one can produce a series of modifications ranging from the very sensitive to the extremely insensitive. One may therefore select, with either method, a test which suits one's own requirements. The majority of workers appear to require simplicity and the minimum of apparatus so that the test may be done in the out-patient department, in the ward, or in the family doctor's surgery, and such a degree of sensitivity as to produce the minimum of false positive results while the patient is on an ordinary diet (Hughes, 1952; Needham and Simpson, 1952; Smith, 1958).

Most workers of this opinion have used the simple slide benzidine test described by Gregersen (1919) in its original or some modified form.
Analysis of the results of Needham and Simpson (1952) shows that only $40 \%$ of their cases with lesions of the upper alimentary canal gave acceptable positive results. A further $14 \%$ gave trace reactions only, and $46 \%$ gave negative results. Nevertheless they found an incidence of about $7 \%$ of unexplained positive results. Dahl-Iversen and Nissen (1930), who used a series of Gregersen's tests in each of their cases, found $7 \cdot 3 \%$ persistently negative and $25.5 \%$ intermittently negative results in cases of carcinoma of the small and large intestine.

Others have used the guaiac test to allow the test to be carried out without dietary restrictions. Hoerr, Bliss, and Kauffman (1949) using it found that over $20 \%$ of their negative results were obtained in cases in which blood would be expected in the faeces, including cases of carcinoma of the stomach, of the oesophagus, and of the rectum. Nevertheless they found eight unexplainable positive results out of 39. With the guaiac test, Mason and Belfus (1952) found that $43 \%$ of their positive results occurred in patients with, and $48 \%$ in patients without, alimentary lesions. The remainder were doubtful or the patients failed to cooperate. Of their negative results, half occurred in patients with gastrointestinal symptoms and $20 \%$ of the total in patients with proven alimentary lesions, including cases of gastric carcinoma. Therefore we must consider whether simplicity of operation and no dieting before the test, at the same time achieving no false positives, are the ideal requirements of a test for occult blood.

The means available to the clinician, other than clinical observation, for the diagnosis of peptic ulceration and gastric carcinoma are, generally speaking, exploratory laparatomy, $x$-ray examination, gastroscopy, and laboratory methods, of which the faecal occult blood test is the most commonly used. Exploratory laparatomy is not often resorted to in the absence of other supporting evidence and cannot possibly be carried out as a diagnostic procedure in every vaguely suspect case. With regard to $x$-ray examinations, Tanner (1944) found that of 631 gastric ulcers seen at gastroscopy, $159(25 \%)$ were not found on $x$-ray examination. In two cases the radiological diagnosis was duodenal ulcer and the final diagnosis gastric carcinoma. Thirteen cases of gastric carcinoma were thought to be benign ulcers or not seen at all at $x$-ray examination. He points out also that the radiological diagnosis of anastomotic ulcers is notably difficult. Schindler (1952) found that of 70 gastric ulcers, $15(21 \%)$ were not seen on $x$-ray examination. In certain instances highly experienced radiologists failed to demonstrate ulcers although they knew in advance that they existed and exactly where. 
Similarly in the series of Needham and Simpson (1952), of 213 cases of duodenal ulcer, $62(29 \%)$ were not found at $x$-ray examination.

With regard to gastroscopy, Schindler reports that $26.5 \%$ of gastric ulcers were not seen by that method and, further, that $7 \cdot 7 \%$ of malignant ulcers of stomach were not diagnosed either by $x$-ray or gastroscopic examination.

We agree, therefore, with Rider and Owens (1954) that 'one may be lulled into a false sense of security by false negative reactions if the occult blood test is insensitive.' They used a sensitive benzidine test and adequate dieting and obtained only $1 \%$ false positive results. Gurling (1951) obtained $10 \%$ false positive results with a similarly sensitive method. We do not agree with Hughes (1952) that Gurling's result 'detract markedly from the clinical significance of a positive result' and stress that at least as important is the clinical significance of a negative result. We note also the high incidence of unexplainable positive results by both Gregersen's and the guaiac tests in undieted patients.

It appears that, while other methods of diagnosis are so uncertain, the clinician should expect more help than is offered by simple insensitive methods of testing for occult blood. With these, half of their cases of alimentary bleeding give negative results, and, on the other hand, of all the negative results, half occur in cases of alimentary bleeding. In addition, they appear to give a high proportion of unexplainable positive results. A test for occult blood should be within the scope of the routine hospital laboratory, but it is allowable that it requires some apparatus, some skill, and some care. It should detect blood when it is present, which means that if the test is to be sufficiently sensitive the patient must be dieted beforehand, and the doctor requiring the test should be aware of the substances which may interfere with it (Bramkamp, 1929; Johnson and Oliver, 1941; Peranio and Bruger, 1951; Hughes, 1952; Needham and Simpson, 1952; Kohn and O'Kelly, 1955) and ensure that they are not allowed to do so. In addition the test should, if possible, give some indication of the level in the alimentary canal at which bleeding is taking place.

Bramkamp (1929) pointed out that 90 times as much blood requires to be given by mouth as to be added directly to a stool to give a positive test for occult blood. We have drawn attention to the incidence of negative tests in the presence of alimentary bleeding, particularly in the case of the upper alimentary tract, and have observed this even with highly sensitive methods (Table VI). The reason for these findings is that haemoglobin on its way down the alimentary canal is converted to protoporphyrin, which gives a negative test for occult blood.
The technique of Snapper (1919) was designed to demonstrate both unaltered blood (haematin) and blood converted to protoporphyrin. We have chosen his technique for the demonstration of protoporphyrin, as the acid porphyrin, and have increased its sensitivity about four or five times. It will be seen (Table II) that this increase in sensitivity would convert false negative and trace reactions into moderate and strongly positive tests. By making the test semiquantitative, and standardizing the method of examination, we have achieved some degree of reproducibility of results. We have not determined the sensitivity of this method in terms of blood loss, but note that Bloem (1933) was able to demonstrate acid porphyrin in faeces in a concentration equivalent to $140 \mathrm{mg}$. haemoglobin per $100 \mathrm{~g}$. moist faeces, or about 1 to $2 \mathrm{ml}$. of blood in an ordinary stool. That Snapper's method is insufficiently sensitive is shown by the results obtained by Gurling (1951). Combining the complete Snapper's test with a benzidine test he found an incidence of $52 \%$ false negatives in cases of peptic ulcer, and of $18 \%$ in cases of gastric carcinoma.

The incidence of strongly positive tests for porphyrin in association with negative occult blood tests is high and, as has been noted, the less sensitive the test for occult blood, the greater this incidence. Such results occur almost invariably with lesions of the upper alimentary canal. Contrary to the findings of Hughes (1952) we have observed many instances of anaemia secondary to alimentary bleeding in which even a sensitive benzidine test has been negative. In such cases positive tests for porphyrin have been of great assistance. We have also pointed out, in connexion with experiments on series of dilutions of blood, that in the presence of anaemia the tests for occult blood become less sensitive, for under these circumstances the loss of haemoglobin into the alimentary canal is correspondingly less.

In persons without alimentary lesions tests for occult blood and for porphyrin should be negative. Of our 30 controls, 20 gave such negative results. In the other 10 (Table IV) there was no case in which some explanation could not be offered for the presence of porphyrin and in only two was there no explanation of positive chemical tests.

In the test series (Table V) certain points of importance are illustrated. In active lesions of the upper alimentary tract, six only gave negative or weakly positive tests for porphyrin, and four of these occurred in patients on antacids. Ryffel and Payne (1923) similarly observed that the test for porphyrin becomes negative when the Sippy method of treatment, incorporating the administration of large doses of antacid, is instituted. Charcoal and certain 
antacids. particularly the salts of bismuth, aluminium, and magnesium, strongly adsorb protoporphyrin and may render this test negative. If the antacid is withdrawn the test becomes positive.

We have also noted that sometimes after a massive haemorrhage the test for porphyrin may become negative while the benzidine test is intensely positive. This lasts for a day or two, and porphyrin rapidly appears in high concentration. One of the remaining two weak results was of this type. In the other we can offer no explanation other than that the patient just was not bleeding at that time.

In healing lesions the test for porphyrin appears to be of value. In lesions of the colon and rectum tests for porphyrin are negative or weakly positive, as would be expected, while chemical tests, provided they are of sufficient sensitivity, are positive (Table $\mathrm{V})$. We have, however, seen a number of cases of carcinoma of the caecum and upper colon in which the test for porphyrin was strongly positive as well as the benzidine test. This exception apart we find that a strongly positive porphyrin test means upper alimentary bleeding.

Congestive cardiac failure almost always gives positive tests for occult blood and porphyrin. The passive congestion of the alimentary mucosa in these cases is a sufficient explanation of the positive findings.

In this series patients with no alimentary lesion gave negative or weakly positive results only, except in a patient with myeloid leukaemia with skin petechiae, in whom positive results would be expected.

We have pointed out that our patients are normally on a diet free of meat and green vegetables before the test, and that we consider an absence of meat of importance in relation to the test for blood. We believe also that it is of importance in connexion with the test for porphyrin, although our experience is at variance with that of Ryffel and Payne (1923) who state that the spectrum of protoporphyrin ('haematoporphyrin') is not found in the faeces following the ingestion of meat. In addition the close similarity of the structure of chlorophyll to that of haemoglobin indicates that it also should be omitted from the diet in a test for porphyrin.

It is possible that certain diseases associated with abnormal porphyrin excretion without alimentary bleeding, such as pernicious anaemia and certain types of porphyria, may cause confusion but do not present a great problem although they should be kept in mind.

In conclusion, we are of the opinion that the test for faecal occult blood should be carried out by a sensitive method and be accompanied by a sensitive test for protoporphyrin. The Hematest method is too insensitive to be of real value and the orthotolidine tube test we describe is little better. The Occultest method is the most sensitive of these three and, in our hands, has about the same degree of sensitivity as Gregersen's slide method, for which it would be a satisfactory and very simple substitute. Also, adequate precautions should be taken regarding diet and drugs given before the test. False positives will inevitably occur but, under these circumstances, many of them may be due to the impossibility of otherwise demonstrating a lesion rather than to its absence.

\section{SUMMARY}

Comparative observations are made on a benzidine test, an orthotolidine test, the Occultest method, and the Hematest method for the detection of occult blood in faeces. The importance of carrying out such comparisons of faecal rather than on watery suspensions of blood is stressed.

A sensitive test for protoporphyrin is described and its value as an adjunct to tests for occult blood discussed. The importance of using sensitive rather than insensitive tests is illustrated, and the necessity to diet the patient before the test and to withdraw interfering substances in the form of medicines discussed.

Our thanks are due to the Ames Company (London), Limited, for generous supplies of Occultest and Hematest reagent tablets, and to the clinical staff of St. Andrew's Hospital who provided the clinical material on which this study is based.

\section{REFERENCES}

Bloem, T. F. (1933). Biochem. J., 27, 121-131.

Bramkamp, R. G. (1929). J. Lab. clin. Med., 14, 1087-1091.

Case, R. A. M., Hosker, M. E., Drever, M.McD., and Pearson, J. T. (1954). Brit. J. industr. Med., 11, 75-104.

Dahl-Iversen, E., and Nissen, N. I. (1930). Hospitalstidende, 73, 543-554. Quoted in J. Amer. med. Ass. (1930), 95, 702.

Gregerson, J. P. (1919), Arch. Verdau.-Kr., 25, 169-195.

Gurling, K. J. (1951). Postgrad. med. J., 27, 345-348.

Harrison, G. A. (1947). Chemical Methods in Clinical Medicine, 3rd ed., p. 310. Churchill, London.

Hoerr, S. O., Bliss, W. R., and Kauffman, J. (1949). J. Amer. med. Ass., 141, 1213-1217.

Hughes, A. (1952). Brit. med. J., 2, 970-975.

Johnson, A. S., and Oliver, E. B. (1941). J. Lab. clin. Med., 26, 727-728.

Kohn, J., and O'Kelly, T. (1955). J. clin. Path., 8, 249-251.

Mason, E. W., and Belfus, F. H. (1952). J. Amer. med. Ass., 149, 1526-1528.

Needham, C. D., and Simpson, R. G. (1952). Quart. J. Med., 21, 123-133.

Peranio, A., and Bruger, M. (1951). J. Lab. clin. Med., 38, 433-445.

Rider, J. A., and Owens, F. J. (1954). J. Amer. med. Ass., 156, 31-33.

Ryffel, J. H., and Payne, W. W. (1923). Guy's Hosp. Rep., 73. (4 ser. 3), 131-136.

Schindler, R. (1952). Med. Clin. N. Amer., 36, 1099-1110.

Smith, R. L. (1958). Brit. med. J., 1, 1336-1339.

Snapper, J. (1919). Arch. Verdau.-Kr., 25, 230-240.

Tanner, N. C. (1944). Brit. med. J., 2, 849-851. 